\title{
TERRENO DO CEMITÉRIO JAPONÊS EM ÁLVARES MACHADO - SP
}

Keiko Kuroiwa, Yeda Ruiz Maria.

Universidade do Oeste Paulista - UNOESTE, Curso de Arquitetura e Urbanismo, Presidente Prudente, SP. Email: yeda rm@hotmail.com

\section{RESUMO}

A abertura dos portos para a vinda de imigrantes asiáticos no Brasil para suprir a falta de mão-de-obra na lavoura foi o início de uma nova oportunidade para construção e uma nova história em busca de melhores condições financeiras, porém, os japoneses ao chegarem nas terras brasileiras depararam com a verdadeira realidade a ser enfrentada. Com o tempo começaram suas buscas por locais para se instalarem no interior paulista, lutaram por suas conquistas e começaram a deixar suas marcas, sendo uma delas o Cemitério Japonês de Álvares Machado - SP, local preservado até os dias atuais pela comunidade japonesa de Álvares Machado - SP, tanto nas tradições quanto nas construções, informações estas também passadas entre gerações por meio de escritas e diálogos.

Palavra-chave: Imigração Japonesa; Cemitério Japonês; Álvares Machado-SP.

\section{LAND OF THE JAPANESE CEMETERY IN ÁLVARES MACHADO - SP}

\begin{abstract}
Opening ports for the arrival of Asian immigrants in Brazil to fill the labor shortage on the farm was the beginning of a new opportunity for construction and a new history in search of better financial conditions, but the Japanese when they arrived in Brazilian lands faced the real reality to be faced. Over time they began their searches for places to settle in the interior of São Paulo, they fought for their achievements and began to leave their marks, one of them being the Japanese Cemetery of Álvares Machado - SP, a place preserved to this day by the Japanese community of Álvares Machado - SP, both in traditions and constructions, information also passed between generations through writing and dialogues.
\end{abstract}

Keywords: Japanese Immigration; Japanese Cemetery; Álvares Machado-SP. 


\section{INTRODUÇÃO}

Em 1808, D. João VI abre os portos e concede "terras aos estrangeiros no Brasil" (TENAKA, 2003, p. 24), liberando a entrada de japoneses e chineses que não respondiam por processos criminais somente em 1892 (BRASIL, 1892), porém, somente no "dia 18 de junho de 1908, aportavam em Santos, os primeiros imigrantes japoneses trazidos pelo lendário vapor Kasato-Maru" (TENAKA, 2003, p. 15) com pessoas em busca do sonho e oportunidade de progredir financeiramente e reiniciar a vida (CARARO, 2017). Deste modo no ano de 2018 a colônia japonesa comemora os 110 anos da imigração no Brasil e 100 anos na cidade de Álvares Machado - SP onde conquistaram, por meio de seus esforços, espaços cheios de histórias e significados.

Ao desembarcarem no Brasil, os japoneses eram encaminhados para a Hospedaria, para alojar e alentar os mesmos "durante oito dias" (NOGUEIRA, 1984, p. 134), espaço este que também serviu para o auxílio na admissão de trabalhadores (NOGUEIRA, 1984).

Para suas vindas receberam auxílio financeiro do governo e de fazendeiros, na qual parte deste empréstimo deveria ser pago com o dinheiro ganho no cultivo de café, no total de "40 ienes ao fazendeiro e depois disso, uma nova vida lhes estaria assegurada" (TENAKA, 2003, p. 40), algo distante da realidade, pois para a própria alimentação, os nipônicos compravam itens nos armazéns das fazendas, assim gerando dívidas, modo este utilizado por fazendeiros para que os imigrantes não tenham dinheiro e continuem trabalhando na lavoura de café (TENAKA, 2003). Enfraquecidos devido à má alimentação e trabalhos duros, foram acarretando várias consequências como doenças que levavam a mortes (SHINDO, 1999; COMISSÃO, 1992).

Segundo Cararo (2017), devido à desenvoltura em cultivos, alguns imigrantes se dispersaram pelo interior do estado de São Paulo para o plantio de alimentos como arroz, frutas, legumes e verduras.

Neste sentido, o presente artigo tem como objetivo abordar a história dos imigrantes nipônicos que se instalarem na cidade de Álvares Machado - SP e o terreno pertencente ao cemitério japonês existente na cidade.

\section{METODOLOGIA}

A metodologia aplicada no presente artigo se deu por meio de analises bibliográficas e documentais para a compreensão dos fatos históricos, levantamento in loco em busca de acervo fotográfico e posteriormente analise sobre as condições atuais das construções existentes no terreno do Cemitério Japonês para o melhor conhecimento do assunto a ser abordado.

\section{ÁLVARES MACHADO - SP}

A construção da estrada de ferro no interior do Estado de São Paulo foi grande influenciador para o começo de uma nova história nas terras virgens do Oeste Paulista, pois foi o alicerce para o início da produção de café (TENAKA, 2003; ABREU, 1972), onde a Empresa José Giorgi responsável pela implantação da linha férrea nesta região de Presidente Prudente - SP desde 1915, deixou Álvares Machado - SP na estaca 2884 (SUZUKI, 2008).

Em 1916, Manoel Francisco de Oliveira viaja para o interior de São Paulo para a compra de glebas, chegando nas terras da antiga Fazenda Pirapó-Santo Anastácio no dia 19 de março do mesmo ano, sendo determinante na escolha e compra a informação da 
construção de uma estação pela Estrada de Ferro Sorocabana, tornando o local "ponta de trilho" (SANTOS, 2006, p. 16).

Em 1921 nascia com o nome Patrimônio São Luiz o parcelamento de terras feita por Manoel Francisco de Oliveira que posteriormente no mesmo ano o Governo do Estado de São Paulo nomeou como cidade de Álvares Machado em homenagem a Francisco Álvares Machado de Vasconcelos, médico cirurgião, pioneiro da oftalmologia no Brasil que se destacou no meio político (SANTOS, 2006).

Em 26 de dezembro de 1927, pela Lei $n^{\circ} 2.242$, o patrimônio foi elevado a Distrito de Paz, pertencente a Presidente Prudente. Em 30 de novembro de 1944 elevou-se a município, sendo agregado a seu território, partes das terras de Presidente Prudente (PREFEITURA DE ÁLVARES MACHADO, p. 02).

Considerada uma região de crescimento do cultivo de café no primórdio do século XX, Álvares Machado - SP, abriga até os dias atuais uma Colônia Japonesa que teve origem no ano de 1918 devido à compra de glebas por "pioneiros ou pessoas previdentes e ambiciosas" (TENAKA, 2003, p. 50).

\section{O CEMITÉRIO JAPONÊS}

No começo de 1918, os nipônicos começaram a adquirir terras na cidade de Álvares Machado - SP e tiveram grande participação na colonização do mesmo (SUZUKI, 2008).

O fator distância e a grande mortalidade foram contribuintes para a abertura do cemitério, pois os corpos eram conduzidos pelas próprias pessoas ou com a ajuda de animais ao cemitério de Presidente Prudente - SP que se localizava onde hoje é a atual rodoviária, totalizando 15 quilômetros (SANTOS, 2006; SUZUKI, 2008). Esta situação fez com que Naoe Ogassawara fizesse o pedido ao Município de Conceição de Monte Alegre para a abertura de um cemitério (SANTOS, 2006).

Ao passarem por Osaka, Japão, o clã Ogassawara recebeu do jornal "Osaka Mainichi Shimbum" (SUZUKI, 2008, p. 26) 500 ienes ${ }^{1}$ para o uso em benefício da colônia, tendo como destino a fundação de um cemitério em um canto de uma área de cinco alqueires e de uma escola (SUZUKI, 2008), que "partir de fevereiro de 1921 [...] começou a tomar forma." (SUZUKI, 2008, p. 28).

Veio a 2a Guerra Mundial, e com o conflito que envolveu o Brasil e outras nações, houve denúncia da existência de um "quisto racial", com um Cemitério exclusivo para os imigrantes japoneses. Getúlio Vargas (Presidente da República) decretou o fechamento do Cemitério em 1943: e desde então, nenhum sepultamento foi feito naquele local (CARARO, 2017, p. 05).

Tombado pelo Conselho de Defesa do Patrimônio Histórico, Arqueológico, Artístico e Turístico - CONDEPHAAT desde 1980, tem sua importância ligada à cultura de modo "etnográfico, histórico, afetivo e [...] estético" (NASCIMENTO, 2005). Onde todos os anos realizam o undo-kai ${ }^{2}$ e desde o ano de 1920 o "Shokon-sai ${ }^{3}$ no segundo domingo do mês de julho no Cemitério Japonês" (TENAKA, 2003, p. 177), neste evento realiza-se uma missa na capela local e "apresentações artísticas no pátio da escola do Shibu ${ }^{4} 1$ " (TENAKA, 2003, p. 120).

\footnotetext{
${ }^{1}$ lenes: Moeda oficial do Japão.

${ }^{2}$ Undo-kai: Gincana poliesportiva em homenagem ao imperador Japonês.

${ }^{3}$ Shokon-sai: Convite às almas para a missa.

${ }^{4}$ Shibu: Divisão feita pelos japoneses na gleba para a construção e administração de escolas primárias.
} 
Terreno este, pertencente à Associação Cultural, Esportiva e Agrícola NipoBrasileira de Álvares Machado, ACEAM, encontra-se distante da malha urbana de Álvares Machado - SP e faz-se o único acesso por meio da Rua Naoe Ogassawara e possui em sua parte interna a Avenida Kurakiti Miyashita que faz ligação da rua de acesso ao cemitério (figura 1).

Figura 1. Terreno do Cemitério Japonês.

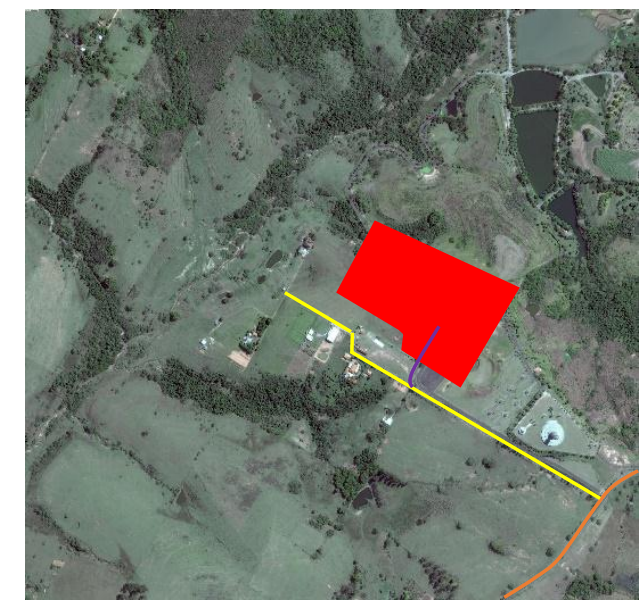

Terreno Vicinal Vereador José Molina Rua Naoe Ogassawara Av. Kurakiti Miyashita Fonte: Google Eartth, 2017; Modificada por Autores, 2018. SEM ESCALA.

Referente aos recursos hídricos, no terreno observa-se um afluente abaixo do cemitério (figura 2) e somente uma bacia seca, tendo a maior parte da vegetação perto desses recursos hídricos e não ocorre a utilização da Lei no 12.651/12, pertinente a Área de Preservação Permanente (APP) em suas margens.

Figura 2. Afluente próximo ao cemitério.

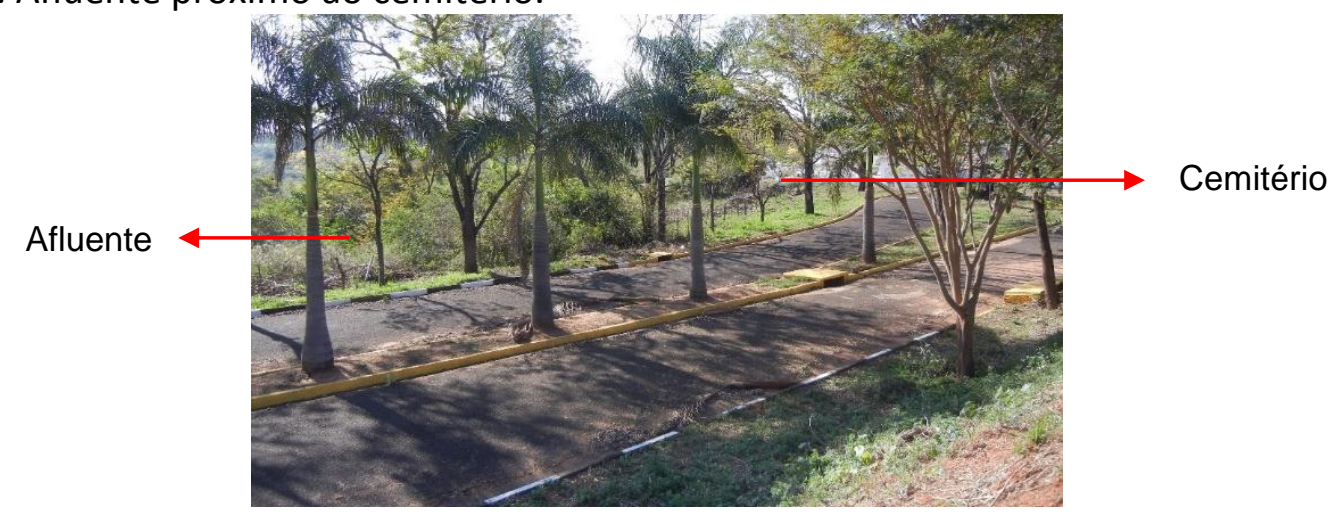

Fonte: Autores, 2018.

Analisando o espaço, pôde-se criar a setorização do local dividindo-o em pastagem, área de eventos, estacionamento, plantação de eucalipto, cemitério e Avenida Kurakiti Miyashita (figura 3). 
Figura 3. Setorização atual do terreno.

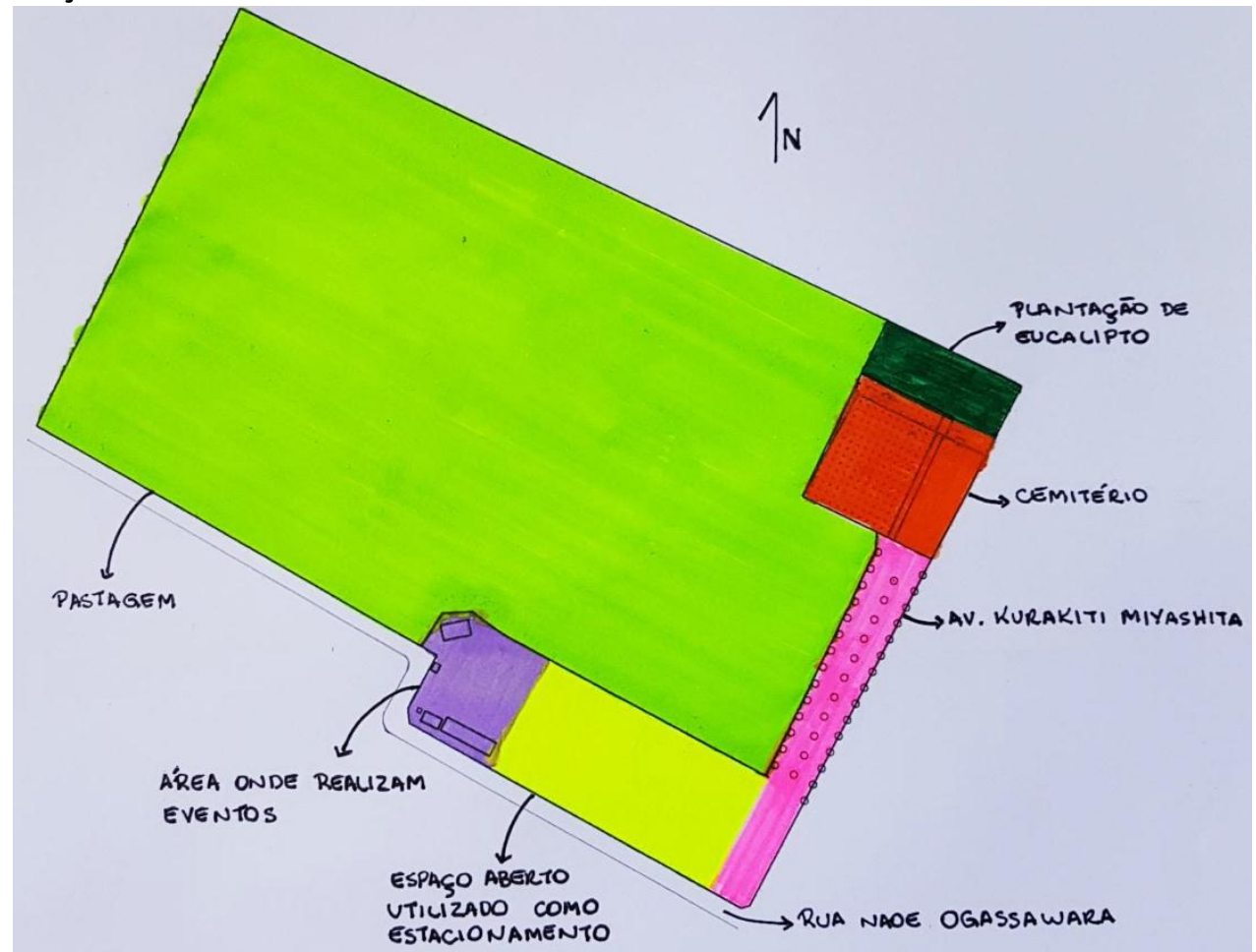

Fonte: Arquivo DWG fornecido por Mario Ogassawara; Modificado por Autores, 2018. SEM ESCALA.

Além do cemitério, no terreno encontra-se a antiga escola, palco, capela, depósitos, sanitários e um espaço utilizado como estacionamento (figura 4).

Figura 4. Construções e espaço utilizado para realização de eventos.

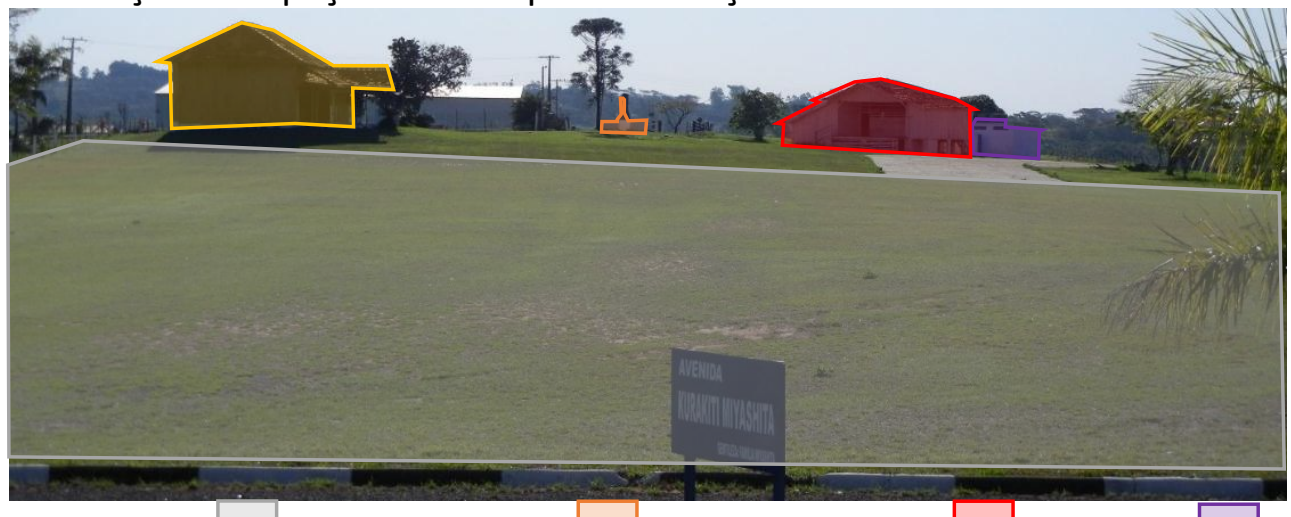

Antiga escola;

Estacionamento;

Monumento;

Palco;

Sanitário.

Fonte: Autores, 2017.

Todas as construções são elevadas por sapatas corridas e pilares para que se tornem planos internamente, exceto os banheiros que pertencem a épocas diferentes e não se pôde identificar o tipo de estrutura de fundação.

Atualmente há grande preocupação da associação em manter viva a memória e a cultura nipônica, porém ao mesmo tempo percebe-se no espaço a falta da manutenção correta do espaço, fazendo com que sofra mais com as ações das intempéries. 
Figura 5. Ação do tempo no palco existente.

Fonte: Autores, 2017

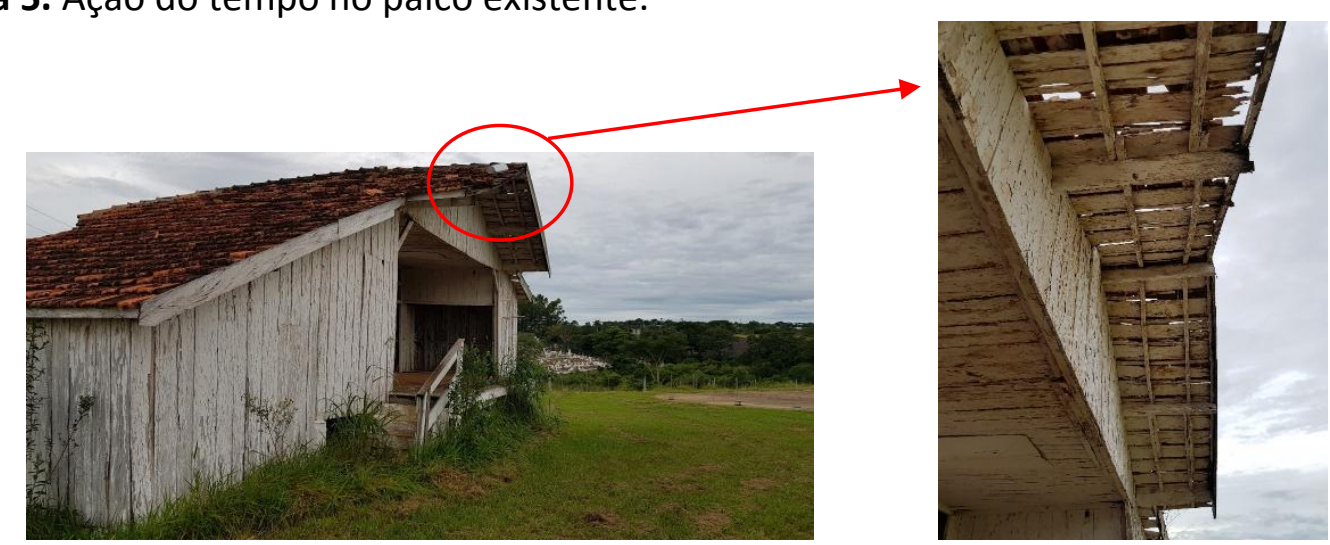

\section{CONSIDERAÇÕES FINAIS}

Apesar das diversas dificuldades encontradas por imigrantes japoneses nas terras brasileiras, tiveram conquistas sendo uma delas o terreno do cemitério japonês na cidade de Álvares Machado - SP, local que mesmo não possuindo muitos usos, é cheio de significados e histórias que não podem ser perdidas com o tempo, ou seja, é necessário a correta manutenção do espaço para evitar uma severa degradação por se tratar de um local considerado importante, não somente para os nipônicos, como também para a região em que está inserida.

O fator ambiental deve ser considerado na alocação de um cemitério, algo não pensado na época pois não existiam leis referentes e mesmo nos tempos atuais é nítido a falta da preocupação ambiental nos afluentes encontrados.

Com base nas pesquisas realizadas percebe-se que por mais que seja um local tombado pelo CONDEPHAAT, a falta de uso que se limita a duas vezes ao ano contribui para o esquecimento do mesmo, tornando-se um espaço não convidativo no dia a dia, deste modo o conhecimento da história torna-se limitado para demais pessoas.

\section{REFERÊNCIAS}

BRASIL. Annaes da Câmara dos Deputados. V.5, 1892.

CARARO, H. Shokonsai: a vida celebrando a morte. 1. ed. Presidente Prudente, SP. 2017.

COMISSÃO DE ELABOBRAÇÃO DA HISTÓRIA DOS 80 ANOS DA IMIGRAÇÃO JAPONESA NO BRASIL. Uma epopeia moderna. São Paulo: Hucitec; Sociedade Brasileira de Cultura Japonesa, $1992 . \quad$ Disponível em: <http://www.imigrantesjaponeses.com.br/iminbrasil/UMA\%20EPOPEIA\%20MODERNA\%208 OANOS.pdf $>$. Acesso em: 26 jan. 2018.

NOGUEIRA, A. R. Imigração Japonesa na História Contemporânea do Brasil. 1. ed. São Paulo: Oficinas da Gráfica Parma, 1984.

SANTOS, V. Álvares Machado de outrora uma grande multidão de rostos e paisagens. Presidente Prudente, SP. Jul. 2006.

SUZUKI, J. P. Álvares Machado, uma saga japonesa. Álvares Machado, SP. 2008. 
TENAKA, E. M. M. Raízes de Um Povo: A Colônia Japonesa de Álvares Machado - SP. 2003. 165 f. Dissertação (Mestrado elaborado junto ao Curso de Pós-Graduação em Geografia) Universidade Estadual Paulista Faculdade de Ciências e Tecnologia, Presidente Prudente SP. 